\title{
Phytochemical and pharmacological activities of Solanum surattense Burm. f.-A review
}

\author{
Siva Kumar Tekuri ${ }^{1}$, Sivarama Krishna Pasupuleti ${ }^{2}$, Kranthi Kumar Konidala ${ }^{1}$, Shobha Rani Amuru ${ }^{1}$, Purusotham Bassaiahgari ${ }^{1}$, \\ Neeraja Pabbaraju ${ }^{1 *}$ \\ ${ }^{1}$ Department of Zoology, Sri Venkateswara University, Tirupati, India. \\ ${ }^{2}$ Lecture in Botany, Govt. Degree College, Chittoor, India.
}

\begin{tabular}{l}
\hline ARTICLE INFO \\
\hline Received on: 07/01/2019 \\
Accepted on: 12/02/2019 \\
Available online: $30 / 03 / 2019$
\end{tabular}

\section{Key words:}

Solanum surattense, traditional medicine, pharmacological activity, solasodine, diosgenin.

\begin{abstract}
Medicinal plants are unique in having the ability to produce diverse chemical compounds with remarkable biological activities. Investigations of medicinal plants resulted in the discovery of a large number of bioactive compounds with excellent therapeutic properties. Solanum surattense, a perennial wild growing medicinal herb, is widely used in the traditional medicine. Exhaustive literature availability reveals the presence of phytochemical compounds from different plant parts like roots, stem, leaves, fruits, and seeds reported to possess a wide range of pharmacological activities like hepatoprotective, cardioprotective, antiasthmatic and mosquito repellents properties. Intensive investigation on phytochemical constituents resulted in isolation of alkaloid and steroidal compounds solasonoine, solamargine, campesterol, and diosgenin. Evaluation of therapeutic activity of isolated compounds proved as potent ones with reference to the standard. Current literature on the pharmacological activity of $S$. surattense confirms the scientific validation of folklore claims and its traditional use to cure various ailments. Present review is undertaken to summarize all the available information on pharmacological activities, which provide a baseline support for further exploration of its unexplored therapeutic effects like immunomodulation, antipiles activity, antianaphylactic activity, and sexual behavior claimed by folklore.
\end{abstract}

\section{INTRODUCTION}

Plants have been used as a potential source of medicine, due to an enormous diversity of bioactive compounds. Many of the plants used in the traditional medicine to alleviate the common ailments and to promote a healthy life. World Health Organization mentioned that $80 \%$ of world population are dependent on the traditional medicine (Sen and Chakraborty, 2016). India possesses well-versed knowledge of the traditional medicine and its practice since from the ancient past. The continuity of the traditional medicinal practice still today, owing to its cure and effective restoration potential. Bioactive compounds from the plant sources have always been of great significance to develop novel therapeutic drugs. In recent years, increased attention toward the

\section{"Corresponding Author}

Neeraja Pabbaraju, Professor, Department of Zoology, Sri Venkateswara University, Tirupati, India.E-mail: pneeraja.bio2015@gmail.com use of herbal drugs has been observed throughout the world. The resurgence in usage of herbal medicine accelerates the research on pharmacological activities of plants used in the traditional medicine.

Solanum surattense (Solanaceae) is a perennial wild growing medicinal herb used as a traditional and folklore medicine. Ancient Indian text Materia medica mentioned the use of $S$. surattense leaves to cure a wide range of ailments. Solanum surattense usually called as Indians nightshade (English), Nelamulaka (Telugu), and Kantakari (Sanskrit). It is a distributed in Australia, Ceylon, India, Malaysia, Polynesia, and Southeast Asia (Parmar et al., 2010; 2017). Commonly found as wild growing plant along the roadsides and dry wastelands. Phytochemical profile of $S$. surattense reported the presence of alkaloids, flavonoids, phenols, and steroids. Clinical studies on antiasthmatic and curing dental inflammation revealed the effective therapeutic potential of S. surattense. Exploration of various pharmacological effects from $S$. surattense emphasized 
the possible use of bioactive compounds to develop novel therapeutic drugs. It's a promising approach in search and development of the modern medicine, based on traditional medicinal knowledge. Present review, aimed to provide deep insights on its wide range of pharmacological activities and clinical studies of $S$. surattense reported from previous studies (Nithya et al., 2018). It also provides the scope to uncover the unexplored potentialities like immunomodulation, antipiles activity, antianaphylactic activity, and sexual behaviour claimed by folklore.

\section{METHODOLOGY}

Solanum surattense synonyms were confirmed through the plant data available site (www.the plant list.org). To present this review, we follow the methodology of collecting enormous data from the most authenticated and scientifically sound sources such as Google Scholar (http://scholar. google.com), data bases include PubMed (http://www.ncbi. nlm.nih.gov/pubmed), Scopus (https://www.scopus.com), Research Gate (https://www. researchgate.net), Science Direct (https://www.sciencedirect. com), SciFinder (http:// www.libnet.ulg.ac.be/en/eresources/ scifinder-scholar), and Web of knowledge for the search terms: folklore medicine, ethnomedicinal, phytochemistry, and pharmacological activities of Solanum surattense and its synonyms also. The literature related to species distribution, synonyms, morphological characters, ethnomedicinal, phytochemistry, clinical study, pharmacological activities, and toxicity of $S$. surattense was included. The phytochemical data were arranged according to category of constituents shown in Figure 2A and B. The selected phytochemical compound structures downloaded from consulting open chemistry database PubChem (http://pubchem.ncbi.nlm.nih.gov/search/ \#collection=compounds), and redrawn through the freeware version of the software ChemSketch.

\section{Morphological Description of Solanum surattense}

Solanum surattense is prickly, diffused perennial herb, about 1.2-m tall usually with woody base. Stem profusely branched, somewhat zig zag, the young branches clothed with dense satellite and tomentose hairs, prickles compressed straight, glabrous, and shiny, often 1-3 cm long, leaves ovateelliptic, deeply lobed, base attenuate, veins and margins with spines. Flowers bluish-pink in extra-axillary racemes. Calyx lobes 5, free, abovate, prickly acuminate. Corolla broadly ovate-triangular, lobes 5 acute. Stamens 5. Fruit-Berry, globose, green with white stripes, yellow when ripe, seeds circular, numerous, and smooth (Singh and Singh, 2010). Its taxonomy and nomenclature are as follows: Plant name: S. surattense; Kingdom: Plantae; Division: Magnoliphyta; Class: Magnoliopsida; Order: Solanales; Family: Solanaceae; Genus: Solanum. Synonyms Latin: Solanum surattense Burm. f Syn; Solanum xanthocarpum Schrad. \& H. Wendl., Solanum virginianum L., Solanum mairei H. Levy. The vernacular names in different regional languages in India are as follows: Telugu: Nelamulaka, Vakudu; Sanskrit: Kantakari, Nidightika; Hindi: Katari; Tamil: Kankan, kattiri; Kanada: Nelagulla; Oriya: Bhejibegun and Ankranti. The habitat of plant represented in Figure 1.
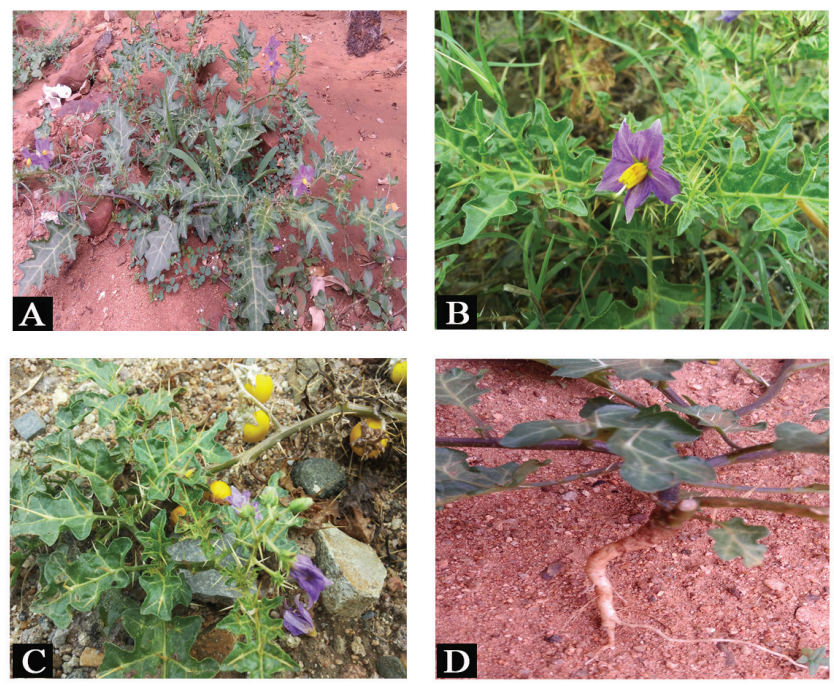

Figure 1. Solanum surattense: (A) habitat, (B) flowering, (C) matured plant with ripened fruits, and (D) root system.

\section{Ethno medicinal usage}

Roots of S. surattense are one of the important constituent of Ayurvedic preparation dashmularishta, used as a tonic for lactating mothers (Sharma et al., 2010). Kondh tribes of Dhenkanal district of Orissa, India are using the hot aqueous extract of the matured fruits as a traditional medicine for the treatment of diabetes mellitus (Parmar et al., 2010). Fruits used as a folk medicine to treat inflammatory problems as well as a throat infection by the local people of Manipur, India. Entire plant used for treating leprosy, dropsy, and cough by the folklore (Madhavi et al., 2014). Mukunda tribes of Rajasthan, India used the root paste for the treatment of hernia (Pandey et al., 2018). Root poultice used to treat the piles are practicing as a traditional medicine in many villages of South India. Seeds along with mustard oil fumigation used as an excellent remedy for the treatment of dental caries, teeth pain, and pus formation and associated swelling of gums (Panday, 2004). Stem, flowers, and fruits are used for relief in burning sensation in feet (Pingale, 2013). Seeds also used as a remedy for cough and asthma (Rahman et al., 2003).

\section{Phytochemical profile}

Roots of $S$. surattense are reported to possess Alkaloids, Flavonoids, Triterpenoids, Tannins, Saponins, Glycosides, and steroids (Ghildiyal and Joshi, 2014; Sahle and Okbatinsae, 2017).

\section{Phytochemistry}

Initially, the $S$. surattense fruits was investigated by the Saiyed and Kanga (1936), and they were used for the isolation of bioactive compounds such as glycoalkaloid (solanosine), steroidal compound (carpesterol) and steroidal alkoloids (caffeic acid, coumarins, and triterpinoids). The fruits of S. surattense possess steroidal alkaloids like solanocarpine, solamorgine, and solanocarpidine (Jayakumar and Murugan, 2016). The other effective bioactive compounds which include polyphenol (caffeic acid), coumarins (esculentin and aesculin), steroids (carpesterol, campesterol, daucosterol, stigmasterol, cycloortanol and cholesterol), 
A Steroids
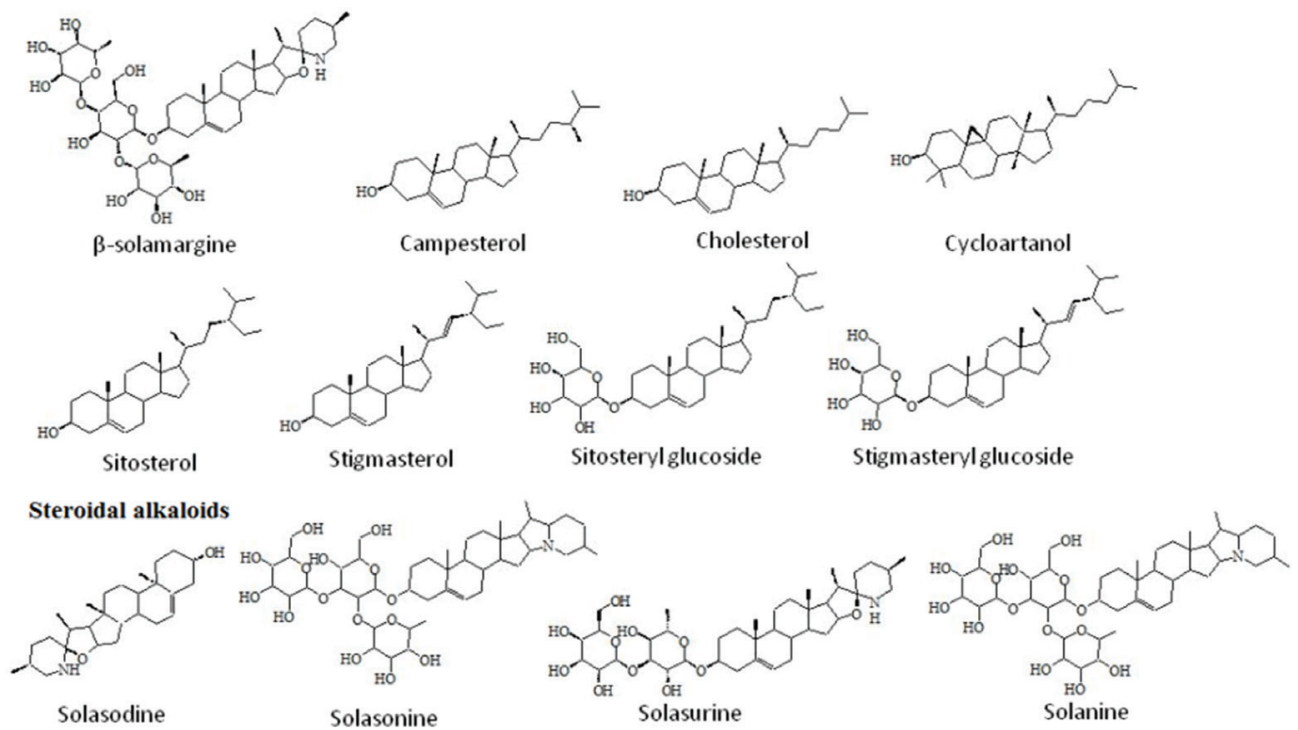

Alkaloids \& glyco alkaloids

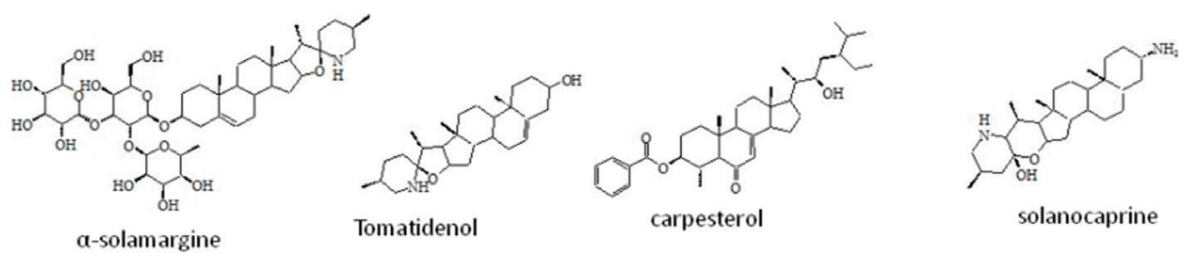

B Flavanoids, Phenolics \& Comarins

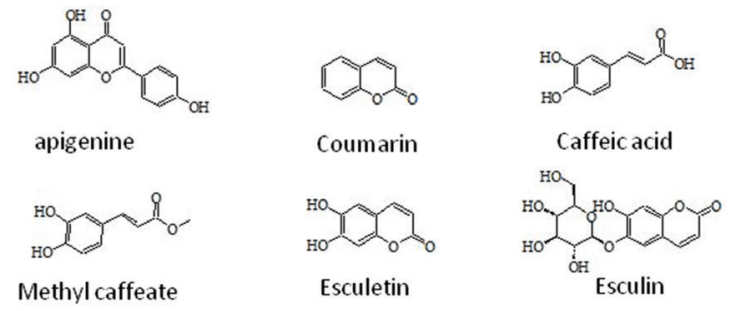

Triterpenoids \& Sapogenin

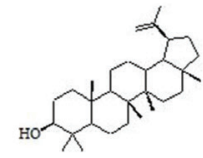

Leupeol

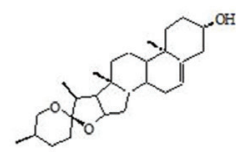

Diosgenin

Fatty acids
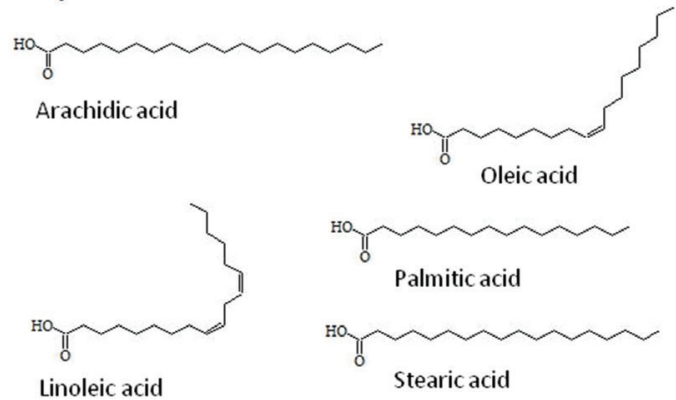

Palmitic acid

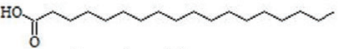

Stearic acid

Figure 2. (A) Steroids, steroidal alkaloids, alkaloids, and glycoalkaloids phytochemical compounds structures isolated from Solanum surattense. (B) Flavanoids, phenolics, coumarins, triterpanoids, sapogenin, and fatty acids isolated compound structures from $S$. surattenese. 
triterpinins and sapogenin (lupeol and diosgenine) have also been reported (Khanam and Sultana, 2012; Singh and Singh, 2010).

Berries of Solanum surattense contain high concentration of an alkaloid solosodine, which is shown the variation in its content in the range of $1.1 \%-4.6 \%$ (Singh and Singh, 2010). Berries collected in autumn (September-October) yielded the alkaloids solasonine and solamorgine. However, the fruits collected in summer (May-June) yielded another alkaloid solasonine (Parmar et al., 2010).

Heble (1971) reported the presence of $\beta$-sitosterol and diosgenin from callus tissues of $S$. surattense. Yield of $\beta$-sitosterol and the diosgenin from callus tissues was much higher than that of naturally grown plant. Further investigation on the fruit extract of $S$. surattense showed the presence of steroidal and alkaloid compounds - cyclocartanol, cycloartinol, sitosterol, stigmasterol, campsterol, sitosteryl glucoside, solamargine, and $\beta$-solamargine. Dry seeds yielded greenish yellow oil rich in fatty acids-linoleic acid, oleic acid, palmitic, steric and arachidonic acid (Heble et al., 1971). Structures of some phytoactive compounds from $S$. surattense are shown in Figure 2A and B.

\section{Pharmacology of Solanum surattense}

Solanum surattense have the several pharmacological activities, proved by scientific observations of experimental works. The bark, leaves, roots and fruits extensively used in traditional medicine due to the presence of several phytoconstituents like alkaloids, terpenoids, saponins, steroids and flavonoids. Scientific evaluations of isolated bio-compounds have ethnomedicinal and novel pharmacological effects (Figure 3).

\section{Antibacterial activity}

Many studies have been carried out with the aim of highlighting the capacities of plant extracts to prevent the growth of the bacterial organisms. Leaf extract of $S$. surattense exert the remarkable effect on bacterial strains. Sheeba (2010) reported a significant antibacterial effect of ethanol extracts of $S$. surattense leaf against eight bacterial strains, Staphylococcus aureus (11.23 $\mathrm{mm})$, Streptococus (9.22 mm), Bacillus subtilis (16.25 mm), Escherichia coli (14.19 mm), Pseudomonas aeruginosa (4.16 $\mathrm{mm})$, Salmonella typhi $(1.16 \mathrm{~mm})$ Vibrio cholera $(10.17 \mathrm{~mm})$. No effect observed with Shigella dysentriea (Sheeba, 2010). Fruits extracts of $S$. surattense exhibited potential effect in preventing the following bacterial strains, Minimum and maximum zones of inhibition observed with Micrococcus luteus $(3.6,12.7 \mathrm{~mm})$ S. aureus $(3.9,14.0 \mathrm{~mm})$ E. coli $(8.6,17.8 \mathrm{~mm})$, S. typhi $(6.5$, $15.7 \mathrm{~mm})$, M. varians $(7.4,10.3 \mathrm{~mm})$ Pasteurella multifida (12.5, $20 \mathrm{~mm})$ V. cholera $(0 \mathrm{~mm})$ (Abbas et al., 2014). Antibacterial efficiency of plant extracts was similar to the efficiency of standard drug ampicillin. Previous studies have reported that the antibacterial activity of $S$. xanthocarpum leaves against the five bacterial stains such as $P$. aeruginosa, S. typhi, S. aureus, E. coli, and Corynebacterium diphtheria (Nithya et al., 2018). Among the solvent extracts, ethyl acetate extracts exhibit moderate and broad spectrum activity against $P$. aeruginosa $(8 \pm 1.2 \mathrm{~mm})$ and $S$. aureus $(7 \pm 1.0 \mathrm{~mm})$, respectively, and does not show inhibitory activity for $S$. typhi. Other solvent extractions, such as chloroform, hexane and acetone exhibited that the very least antibacterial activity against the $S$. aureus, $P$. aeruginosa, and $C$. diphtheriae.

\section{Antifungal activity}

Solanum surattense extract are evaluated for antifungal effectiveness and a wide range of zone of inhibition has been evidenced against many of the fungal stains such as Trichoderma viride, Aspergillus niger, A. flavus, and A. Fumigatas.

Singh et al. (2007) reported antifungal efficiency of isolated steroidal glycosides (carpestroal) on $T$. viride and A. niger. Trichoderma viride exhibited the highest susceptibility and showed the highest growth inhibition antifungal effect of plant extracts were similar to that of standard drug amphotericin-B. In comparison with the fruit extracts, it is less than the effect of standard drug because of the low dose of antifungal components.

\section{Antioxidant activity}

Antioxidants are capable of damaging the reactive oxygen species (ROS), that cause oxidative damage. Free radicals react with the bio molecules like DNA, proteins lipids and produce the toxic effects. So far, a large number of plants reported to possess anti-oxidant potential due to rich phytochemical constituents like phenols and Flavonoids. Yadav et al. (2014) reported the total phenolic and flavonoid content from leaf [25.91 gallic acid equivalent (GAE)/mg b.w] [17.7 Quercitien (QE)], stem (5.879 GAE/mg b.w) (3.129 QE), and fruit (4.975 GAE/mg b.w) (5.208 QE) phenol quantity expressed as GAE and flavonoid content as Quercitien. The leaf contains high quantity of phenols and flavonoid than the stem and fruits. Muruhan et al. (2013) evaluated the ROS scavenging efficiency of $S$. surattense leaf extracts against 2,2-diphenylpicrylhydrazyl scavenging activity, revealed that the plant extract exhibited remarkable antioxidant activity at all test doses in a dose-dependent manner. Fruit extracts also reported to possess appreciable amount of radical scavenging activity (about $80 \%$ ) at the lowest test conc. $(250 \mu \mathrm{g} / \mathrm{ml})$. No enhanced activity was observed at increased test dose conc. 500 and $1,000 \mu \mathrm{g} / \mathrm{ml}$, due to saturation effect (Rehman Shah et al., 2013). Similar findings also noticed from anti-oxidant studies of $S$. surattense fruit extracts (Kumar and Pandey, 2014).

Poongothai et al. (2014) reported that S. surattense leaf extracts enhanced the level of anti-oxidant enzymes catalase (CAT), superoxide dismutase (SOD), and glutathione (GSH) peroxidase in alloxan-induced animal models. Plant extracts increased the anti-oxidants to normal level and the efficiency was similar to standard drug glibenclamide. Remarkable anti-oxidant potentiality of $S$. surattense leaf extracts might be attributed to the presence of phenolic and flavonoids compounds in high quantity (Poongothai et al., 2014). All these findings confirm $S$. surattense to be an ideal choice to pursue the further exploration in developing the effective natural anti-oxidants.

\section{Mosquito larvicidal effect}

Mosquito larval diseases such as malaria, dengue, filariasis, yellow fever, and Japanese encephalitis are prevalent in the tropical countries. The concentration of large number of mosquito vector species in the tropical region increases the risk to affect from the above diseases. The control of mosquito born disease such as malaria is becoming increasingly difficult, because of development of resistance in mosquitoes made the vector control strategy ineffective. Application of chemical and synthetic larvicides to control the larval vectors resulted in the 


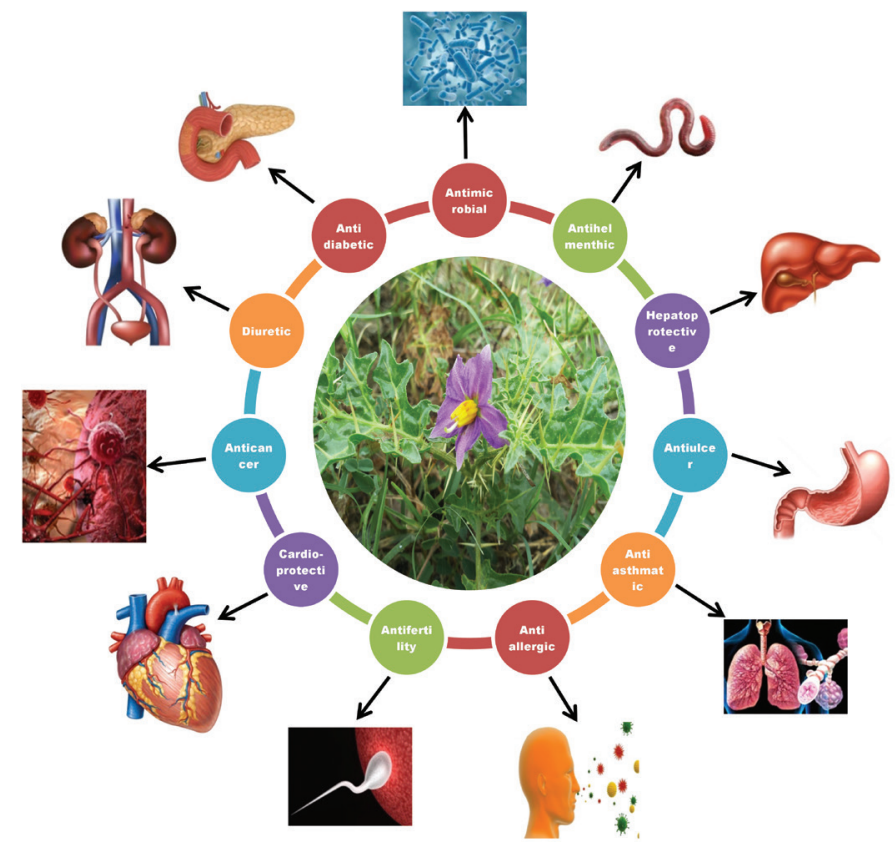

Figure 3. Graphical representation of pharmacological activities reports in $S$. surattense.

development of insecticide resistance and adversely affects the environment by contaminating the soil, air and soil due to their hazardous and persistence properties. Environmental degradation, bio magnification, and increased resistance in mosquitoes for dichloro diphenyl trichloroethane are a well-known fact. Most efficient approach is to control the mosquito vectors during the stage of larval development. Nature has given the plants, which destroys the mosquitoes during larval stage. Bansal et al. (2009) reported the larvicidal efficiency of S. surattense fruit extracts against four vector species such as Anopheles culifacius, Anopheles stephensi, Aedes aegypti, and Culex quinquefasciatus. Anopheles sps are the important vectors of malaria, whereas A. aegypti cause dengue and Culex cause filariasis. Anopheles culifacius showed more susceptibility, followed by A. Stephensi, A. Aegypti, and C. quinquefasciatus. Among the extracts of different parts like whole fruit, seeds, and fruit without seeds, seed extracts exhibited potential larvicidal efficiently followed by whole fruit and the least by fruits without seeds (Bansal et al., 2009). Mohan et al. (2005) reported that, along with the fruits, the roots of $S$. surattense also effective against larvae of A. Stephensi and Culex sps. Subsequent studies carried out by Mohan et al. (2007) synergistic effect of S. surattense root extract and synthetic pyrethroid cypermethin in 1:1 ratio exhibited the highest mosquito larvicidal efficiency than the other test ratios 1:2 and 1:4. Previous study with root extract of $S$. surattense confirmed the mosquito larvicidal property and its efficiency further enhanced by the cypermethrin due to synergism. Similar studies carried out by Bansal et al. (2015) reported that the synergetic efficiency of the S. surattense and Withania somnifera against the larval vectors of three mosquito vector species like A. stephensi, A. aegypti, C. quinquefasciatus. Among the three, A. stephensi was more susceptible to the test ratio 1:3 Ws: Ss. Individual extracts, $S$. surattense had shown more effectiveness as compared with the $W$. somnifera with all three vector species. The larvicidal efficiency was higher with increased in proportion of $S$. surattense and get decreased with increase in proportion of $W$. somnifera extract (Bansal et al., 2015). Leaf extract of $S$. surattense also reported to possess larvicidal efficiency against $C$. Quinquefasciatus (Mahesh Kumar et al., 2012). Hence, from the above findings, it was clear that $S$. surattense possess individual and synergetic mosquito larvicidal efficiency. These studies considered to be of great importance in notifying the potential larvicidal compounds from the natural source.

\section{Antimalarial activity}

Emergence of malaria in many parts of world due to the development of resistance of vectors. Availability of the antimalarial drugs also associated with some side effects because of its synthetic chemical nature. This necessitates searching the safe and effective antimalarial drugs alternative to the existing ones (Antony and Parija, 2016). Traditional medicinal knowledge yields the anti-malarial drugs like quinine and artemesin and their efficiency to control the malaria, stimulated many researchers to find the similar potential anti-malarial drug from the plant sources (Pulice et al., 2016). Ramazani et al. (2010) reported that S. surattense possess anti-malarial activity. Solanum surattense extract exhibited antiplasmodial activity with an $\mathrm{IC}_{50}=50 \mu \mathrm{g} /$ $\mathrm{ml}$ on $\mathrm{K} 1$ strain (Plasmodium falciparum resistant), $\mathrm{IC}_{50}=40.88$ $\mu \mathrm{g} / \mathrm{ml}$ on chloroquine-sensitive strain (Chloroquine-sensitive). Recently, Kaushik et al. (2015) reported that the antiplasmodial activity of $S$. surattense aerial part extraction (ethyl acetate) against the $P$. falciparum. Accordingly, the $\mathrm{IC}_{50}$ of $P$. falciparum 3D7 strain was showed $17 \mu \mathrm{g} / \mathrm{ml}$ and Indonesia strain of $P$. falciparum strain showed $7(0.41) \mu \mathrm{g} / \mathrm{ml}$ values. In addition, the cytotoxicity $\left(\mathrm{TC}_{50} \mu \mathrm{g} / \mathrm{ml}\right)$ of $S$. surattense showed $75(10.7)$ $\mu \mathrm{g} / \mathrm{ml}$ against HeLa cell lines.

\section{Antihelmenthic activity}

Priya et al. (2010) evaluated the antihelmenthic activity of $S$. surattense whole plant crude aqueous, hydroethanolic, and ethanolic extracts at 25,50 , and $100 \mathrm{mg} / \mathrm{ml}$ conc. in distilled water. Piperazine citrate $10 \mu \mathrm{g} / \mathrm{ml}$ used as a reference standard. The study revealed ethanolic plant extracts $(100 \mu \mathrm{g} / \mathrm{ml}$ conc.) showed the remarkable antihelmenthic property than aqueous and hydroethanolic extracts. Barik et al. (2018) noticed similar findings on the antihelmenthic efficiency of $S$. surattense fruit ethanolic and aqueous extracts.

\section{Anti-asthamatic activity}

Asthma, a chronic inflammatory disease affects airway by obstruction, eosinophilia, and bronchial hyper responsiveness (Zanini et al., 2015). Asthma became a global health problem result from a complex interaction between genetic and environmental factors. Use of bronchial dilators and steroidal inhalers, the effectiveness is only limited to mild-to-moderate asthma. However, the use of steroidal related medications has not been right solution because some adverse effects are also associated with that. Literature reveals many plants are reported to have welldefined anti-asthmatic agents and for some agents, the possible anti-asthmatic mechanism was explored. In search of safe and effective medicine from the plants to cure asthma, S. surattense 
considered as the right choice, because of long usage in Ayurveda and siddha as effective to cure respiratory disorders (Babu et al., 2009). Anti-asthmatic efficiency studies on $S$. surattense flower extracts revealed that the presence of anti-histamine and mast cell stabilizing efficiency.

\section{Clinical studies}

Shirishadi, a polyherbal drug used to treat asthma, $S$. surattense forms one of the important constituent. Clinical studies on 60 bronchial asthmatic patients resulted that significant improvement in pulmonary expiratory flow rate (PEFR), forced vital capacity (FVC), and forced expiratory volume (FEV). A constant change was observed throughout the follow up, no resume of bronchial constriction. Clinical trials proved that antiasthmatic potentiality of polyherbal drug for the management of asthma (Divya et al., 2013).

Govindan et al. (1999) studied the clinical efficiency of S. surattense on bronchial asthma, by the administration of single dose $(300 \mathrm{mg})$ to the patients suffering from mild-to-moderate asthma, resulted that relief from asthmatic symptoms were observed after 1 hour and its effect lasted for about 6-8 hours. Potentiality of the plant extracts was evidenced in values of PEFR, $\mathrm{FVC}, \mathrm{FEV}$, and forced expiratory flow confirm the improvement of the pulmonary function. The anti-asthmatic response observed for $S$. surattense is apparently less than compared with that of standard bronchodilator drug Salbutanol and deriphillin. No untoward effects noticed during the study. The low response of the $S$. surattense extracts due to the crude form of drug or less effective dose. Administration of plant extract for 3 days resulted in the progressive improvement in respiratory function of asthmatic individuals. Significant improvement in PEFR and the reduction of other symptoms like cough, breathlessness, and the formation of sputum clearly indicate its potential bronchodilator effect. The effective response exhibited by plant extracts was equivalent to that of standard drug deriphylline, but less than salbutamol. Clinical studies confirm the traditional use of $S$. surattense in bronchial asthma. Accordingly, S. surattense has been defined as the ideal candidate for the modern medicine towards asthma.

\section{Anti-cancer activity/apoptosis}

Plants serve as an excellent source of anticancerous drugs. The success of plant-based anti-cancerous drugs like vinblastine, vincristine, podophyllotaxin, and campothecins... etc. inspires the researchers to continue the search for new anticancerous agents from plants. Anticancerous efficiency of $S$. surattense further widens the pharmacological properties. The anti-cancerous efficiency of $S$. surattense due to the presence of secondary metabolites of Lupeol, apigenin, solamargine and diosgeninas. Solamargine, a steroidal alkaloid possess antitumor effect (Burger et al., 2018). Kuok et al. (2000), tested the anticancerous property of solamargine (glycoalkaloid) on human hepatoma cells (Hep3 cells). Two hours incubation with a constant concentration of solamargine triggered the apoptosis of maximum number of Hep3 cells. Cells in $\mathrm{G}_{2} / \mathrm{M}$ phases are relatively susceptible to apoptosis mediated by solamargine. The possible mechanism of solamargine-mediated apoptosis is due to up regulation of tumor necrosis factor (TNF) receptor-I and II on Hep3B cells. TNF-I or II specific antibody neutralizes the cytotoxicity mediated by solamargine strengthened the underlying mechanism of solamargine-mediated apoptosis of He3B cells. Kumar and Pandey (2013) evaluated the anticancerous efficiency of fruit extract of $S$. surattense on human lung cancer cell lines (HOP-62) and leukemic (THP-1) cell lines. Non-polar extracts (hexane, benzene, chloroform, and ethyl acetate) exhibited potent anticancer activity against THP-1 cell lines (85\%-90\% growth inhibition). Chloroform and benzene fractions accounted for about $70 \%$ cytotoxicity against lung cancer cell lines (HOP-62). The anticancer efficiency of $S$. surattense of fruit extracts on THP-1 cell lines established a positive correlation between flavaniod content and percentage of growth inhibition in cell lines. Anticancerous efficiency of $S$. surattense fruit extracts might be attributed to the presence of flavanoids such as apiginene, quercitien, fisatin, and luteolin, which known to be the potent inhibitors of cancer cell proliferation (Kumar and Pandey, 2014). Solamargine and solasodine are cytotoxicity to Hep 2 B cells of $10 \mu \mathrm{m}$ (Cham, 2017). Diosgenin exhibited apoptosis activity on HCT 116 cell lines (Human colon carcinoma cell lines) (Sethi et al., 2018). The apoptotic efficiency was weak by comparison to the standard drug cisplatin (Bhutani and Paul, 2010). The presence of 2- rhamnose moiety of solamargine and solasonine was essential for apoptosis induction. Solasodine and diosgenin, do not contain carbohydrate moieties, were only weakly cytotoxic. These findings of the study confirm the apoptosis inducing activity and to cause cell death, by the steroidal constituents from $S$. surattense. Thorough systematic investigations required to understand the detailed mechanism of inducing apoptosis and cell death, to develop the potential therapeutic drug to overcome cancer.

\section{Anti-HIV activity}

Kumar and Pandey (2014) reported that the fruit extract of $S$. surattense possess anti-reverse transcriptase (RT) activity. Non-polar extracts (hexane, benzene, chloroform, ethyl acetate, and acetone) and aqueous extracts at dose 0.6 and $6.0 \mu \mathrm{g} / \mathrm{ml}$ are tested to evaluate the anti-RT activity. Results revealed that nonpolar extracts showed that dose-dependent inhibitory activity. Benzene and acetone extracts at $0.6 \mu \mathrm{g} / \mathrm{ml}$ conc. exhibited the highest $(20 \%)$ percentage of RT inhibition, whereas extracts at 6 $\mu \mathrm{g} / \mathrm{ml}$ conc., benzene exhibited the highest $(25 \%)$ percentage of RT inhibition followed by hexane (20\%) and chloroform $(15 \%)$. However, the fruit extracts (non-polar) of S. surattense showed lower percentages of RT inhibition with reference to the standard drug Nevirapine.

\section{Analgesic activity (reducing the tooth pain)}

Panday (2004) reported that seed fumes of $S$. surattense used for the treatment of tooth pain and pain from gingival swellings. Trials done on patients suffering from dental caries, pain, and pus formation, $75 \%$ of them completely cured after 3-4 hours. Effective results find in patients suffering from dental caries associated with severe swelling and pain. Vijay Amirtharaj et al. (2015) reported that, experimental studies on 50 patients suffering from dental problems such as pulpitis, treated with mouth rinse solution (single dose) made from $S$. surattense seed extracts. Test results showed $68 \%$ of the patients in the experimental group, got the relief after the treatment. These findings confirm the efficiency of $S$. surattense seeds to cure 
certain ailments like dental caries, swellings, and tooth pain and considered to be an alternative and safe medicine to cure the dental problems.

\section{Anti-inflammatory activity}

Inflammation is a complex set of interactions between cells and soluble factors that arise in the tissues in response to the infection, trauma, or injury. Inflammation is one of the major constraints results in human diseases like heart disease and diabetes. The choice of non-steroidal and steroidal drugs has side effects. This necessitates searching safe anti-inflammatory agents from the natural source. Fruits of $S$. Surattense are used as anti-inflammatory agents used in the traditional medicine. Investigation of anti-inflammatory efficiency of $S$. surattense extracts on inhibition of paw edema in animal models revealed that only moderate inhibition was observed (Ramanarayana Reddy et al., 2014). However, the contrary findings observed from the studies of Anwikar and Bhitre (2010) Synergistic antiinflammatory effect of $S$. surattense was also observed with Cassia fistula (1:1 combination), the efficiency was slightly less (75\%) than compared with that of the standard drug Diclofenac sodium ( $81 \%$ ), but individually it is $66.41 \%$ with $S$. surattense. Isolated steroidal compounds from $S$. surattense, stigmasterol, carpesterol, and diosgenin also reported to possess anti-inflammatory activity. Among the three, diosgenin found to possess remarkable antiinflammatory efficiency.

\section{Antidiabetic activity}

Prevalence of diabetes throughout the world necessitates the in-search of new, effective, and anti-diabetic drugs than the existing ones. Extensive research going on along these lines and reported many plants have to possess a wide range of antidiabetic compounds, among the reported ones S. surattense possess prominent anti-diabetic potentiality equal to the standard drug Glibenclamide. Leaf extracts of $S$. surattense effectively lowered the blood glucose levels and increased the level of insulin (Poongothai et al., 2014; Sridevi et al., 2007). Antidiabetic studies validate the traditional use of $S$. surattense fruits by the folklore as an anti-diabetic agent. Comparative studies in the field and in vitro grown $S$. surattense plants for antidiabetic activity. Poongothai et al. (2014) noticed that remarkable anti-diabetic efficiency of in vitro grown plants compared with the field grown plants. Availability of the rich source of mineral nutrients during culture conditions, rendered the plants rich in phytochemical, resulted in exhibiting high potential. These findings enabled the use of in vitro techniques to raise the plants, which provide the source of therapeutic drugs with high potentialities (Poongothai et al., 2014).

$\beta$-Sitosterol, a phytosterol from $S$. surattense also reported to possess anti-diabetic properties. A study carried out for duration of 21 days in experimental animal models resulted that increased level of serum insulin was observed in $\beta$-Sitosteroltreated group than compared with the normal ones. The pancreatic protein content estimation, normal in the treated group (diabetic induced), but enhanced level of pancreatic protein observed in normal ones (Control) in a dose-dependent manner. The level of anti-oxidants lipid peroxide, GSH peroxidase, GSH, SOD, and CAT of pancreatic tissue were significantly increased in
$\beta$-Sitosterol-treated group. These findings confirm the protective role of $S$. surattense extracts in preventing from the effects of diabetes induced oxidative damage (Gupta et al., 2011a).

\section{Hepatoprotective activity}

Hepatic diseases are one of the most serious and common diseases to the mankind. Pathogenesis of the hepatic diseases, due to the oxidative stress and inflammation. Despite, tremendous advances in the modern medicine, the management of liver disease is still a major challenge. Solanum surattense fruits used as a traditional medicine to treat the disorders of the liver. Investigations of hepatic protective nature of $S$. surattense leaf and fruit determined its potentiality as an effective hepatic agent. Hepatotoxicity induced by carbon tetrachloride $(\mathrm{CCl} 4)$ resulted the necrosis of hepatic cells and increased the level of serum marker enzymes [aspartate aminotransferase (AST), alanine aminotransferase (ALT), and alkaline phosphatase level (ALP)]. Administration of the fruit extract at dose $400 \mathrm{mg} / \mathrm{kg}$ showed a significant effect on lowering the serum marker enzymes AST (67.71), ALT (75.66), and ALP (54.52). Reduction in the level of serum marker enzymes with plant extracts was similar to the effect of standard drug Silymarin AST (70.31), ALT (77.40), and ALP (59.80) (Gupta et al., 2011b; Jalali Ghassam et al., 2014). Singh et al. (2015) noticed the similar findings of $S$. surattense fruit extracts against paracetamol and azithromycin induced hepatic injury. Leaf extracts, at low test dose $(100,200 \mathrm{mg} / \mathrm{kg})$, resulted in a marginal increase of CAT, SOD, and GSH enzymes, whereas a higher dose restored the level of anti-oxidant enzymes. Solanum surattense extracts offered the hepatic protection, by reducing the oxidative stress induced by $\mathrm{CCl} 4$. These findings support the use of $S$. surattense fruits as a traditional medicine.

\section{Antiulcer activity}

Investigations on antiulcer potentiality of $S$. surattense leaf extracts by Bahuguna et al. (2008) revealed that alcoholic extracts exhibited significant antiulcer property than other solvent extracts. Plant extract raises the $\mathrm{pH}$ (3.10) of gastric contents and lowered the total acidity resulted in decrease of ulcer index. The antiulcer efficiency of $S$. surattense was comparable to the effect of standard antiulcer drug Omeprazole in lowering the acidity. Omeprazole exhibited pronounced effect in decreasing the ulcer index than the plant extracts. The lowered efficiency of plant extracts due to less quantity of anti-ulcer agents in crude form (Bahuguna et al., 2008).

\section{Wound healing activity}

Wounds (Physical injuries) and wound infections are the most common diseases overcome by wound healing. Wound healing restores the disturbed anatomical continuity and normalizes the epithelial integrity of the skin (Gonzalez et al., 2016). Many plants used as a remedy for wound healing, in traditional system of the medicine. Investigations on the wound healing property of various plants led to the discovery of a large number of wound healing agents from plants. Inquisitiveness to develop effective wound healing agents continued to screen many medicinal plants, used in traditional system of medicine. Solanum surattense fruit poultice used traditionally for wound healing (Kumar et al., 2010). Dewangan et al. (2012) reported the $S$. surattense extract (ethanol) 
exhibited pronounced wound healing activity than compared with other solvent extracts. Reduction in epithelisation, time, and scar area in test group due to increased hydroxyproline content and high tensile strength, which is an indication of quality of wound healing. The wound healing efficiency of plant extracts was similar and comparable to the efficiency of standard drug Sulphadiazine. This study provides a scientific support on the account of $S$. surattense use as a traditional wound healer. To use $S$. surattense, active principles in modern medicine need further investigation for isolation and to carry out biological tests to confirm the role of specific compounds in wound healing.

\section{Diuretic activity}

Investigations of Ahmed et al. (2016) on diuretic and serum electrolyte regulation properties of $S$. surattense fruit extracts revealed that fruit extracts significantly increased the urine output in a dose-dependent manner. The diuretic potentiality of plant extract was slightly less than compared with the efficiency of standard drug furosemide (Ahmed et al., 2016). Fruit extract exhibited the diuretic activity by increasing the osmolality of urine together with excretion of electrolytes, due to the presence of phenolic caffeic acid and methyl caffeates as secondary metabolites (Patel et al., 2012). Regarding the serum electrolytes, fruit extracts reduced the level of sodium, potassium, and calcium whereas serum bicarbonates concentration was increased in a dose-dependent manner. Treatment with fruit extracts result a substantial decrease in blood urea nitrogen and $\mathrm{Ca}^{2+}$ proved its diuretic potential. Similar findings noticed with leaf extracts by Ramanarayana Reddy et al. (2014) strengthen the diuretic efficiency of $S$. surattense extracts.

\section{Anti-hyperlipedemic activity}

Total cholesterol, Triglycerides, Phospholipids, and free fatty acid levels in plasma are the significant biomarkers, to assess the hyper or hypolipidemic. Sridevi et al. (2011) carried out the biochemical studies on strepptozotocin induced experimental animal models. very low-density lipoprotein cholesterol and lowdensity lipoprotein cholesterol levels increased and high-density lipoproteins cholesterol levels decreased, reflects the altered lipoprotein profile. Animal models treated with $S$. surattense plant extract normalized the plasma lipid profile than compared with control group (without treatment). The anti-hyperlipedemic potentiality of $S$. surattense was equal to the effect of standard drug Glibenclamide (Sridevi et al., 2011). This study confirms the potential ability of $S$. surattense, as anti-hyperlipedemic agent and provides a scientific rationale for the use of $S$. surattense for the development of effective medicine to combat diabetes and its associated effects on body metabolism.

\section{Analgesic activity}

Solanum surattense leaf extracts have the potential capability to use as an analgesic. Studies in experimental animals with plant extract showed an elevated response in the dose-dependent manner. This investigation authenticates the traditional use of $S$. surattense as analgesic and provides the scope to develop natural analgesics from the folklore claims (Huque et al., 2015).

\section{Anti-urolithiatic activity}

Urinary calculi are the most prevalent disorder of the urinary system. Urinary calculi formed from the oxalates of calcium, phosphates, etc. affect the renal function and decreasing the glomerular filtration rate due to obstruction to the flow of urine (Alelign and Petros, 2018). A large number of plants are used to cure urinary calculi, since from ancient times. Ancient literature Ayurveda describes the traditional use of $S$. surattense for the treatment of urolithiasis. Chauhan et al. (2009) reported the ethnopharmocological use of $S$. surattense for the treatment of urinary track and kidney stones in Muzaffarnagar, U.P (India). Experimental models treated with ethylene glycol for a period of 28 days resulted, the increase in excretion of $\mathrm{Ca}^{2+}$, phosphate, uric acid and a decrease in citrate and magnesium content in urine due to impairment of renal function. Treatment with $S$. surattense extracts improved the renal function by its potential effects like diuretic; anti-oxidant reduced the Caox crystal formation. The decreased levels of $\mathrm{Ca}^{2+}$ and uric acid was evidenced in plant extract treated group indicates the improvement of renal function and confirms its antiurolithiatic role. Similar studies with saponins rich fraction of $S$. surattense fruits resulted that, less number of calcium oxalate crystals and their aggregation in plant extract treated group. Plant extract prevents the formation of calcium oxalate crystals as well as their aggregation (Patel et al., 2012). The anti-urolithiatic efficiency was slightly less compared with the standard drug Cystine. This study confirms the traditional use of $S$. surattense fruits for urolithiasis as effective medicine.

\section{Cardio-protective activity}

Myocardial injury results from the prolonged myocardial ischemia with necrosis of myocytes due to interruption of blood supply to an area of heart (Hashmi and Al-Salam, 2015). According to $\mathrm{WHO}$, it is the leading cause of morbidity and mortality throughout the world (Wunsch and Gourbin, 2018). To overcome the myocardial infarction, effective and safe medicine is an immediate concern. Pullaiah et al. (2015) studied the cardio protective efficiency of $S$. surattense extracts against Isopropanol induced myocardial injury in animal models. Enhanced level of marker enzymes lactate dehydrogenase (LDH) and creatine kinase-muscle/brain (ck-MB) is observed in plasma of myocardial injured animal models. Isopropanol induced myocardial injury is mediated via the $\beta$ - adrogenic receptor. Acute $\beta$ - adrogenic receptor stimulation rapidly generates ROS and also depressed the total anti-oxidant capacity. Treatment with plant extracts showed significant cardio protection in a dose-dependent manner with reference to the standard drug propanol. Potapovich et al. (2012) and Witaicenis et al. (2013) reported the presence of seven kinds of flavonoids and coumarins like esculentin. Esculentin is particularly well proven anti-inflammatory and anti-oxidant activity, which plays a prominent role in healing of myocardial injury. Elevated levels of serum cardiac markers like LDH and cK-MB are drastically reduced because of the presence of cardio protective agents of $S$. surattense. The cardio protective mechanism of $S$. surattense appears to be through improvement of overall anti-oxidant defense mechanism of cardiac tissue. Increased anti-oxidant defense mechanism was evidenced, in the 
level of anti-oxidants like GSH, SOD, and CAT in animal models treated with plant extract.

\section{Antifertility activity}

Antifertility control the population explosion and also provides a plausible solution to the number of problems what the world confronts. Contraceptive methods, most of the choices, are antifertility agents. Contraceptive drugs available are synthetic/ chemical and in many cases found the side effects. Hence, there is a need to replace the chemical drugs by the safe herbal drugs. Many plants have been used as antifertility agents in traditional medicine, but a very few of them evaluated scientifically. Among the contraceptives, availability of male infertility agents is meager. Development of male infertility agents considered to be a potential area of the investigation. Research studies on $S$. surattense reported to possess excellent antifertility activity. Administration of fruit extracts at dose $0.5 \mathrm{mg} / \mathrm{kg}$ for duration of 60 days to experimental animal models resulted that arresting the process of spermatogenesis. It was also evident that reduced number of primary and secondary spermatocytes and spermatids correlated with arresting of the spermatogenesis. In testis, leading cells were also significantly decreased, confirms the antispermatogenic nature of S. surattense fruit (Purohit, 1992).

The S. surattense seed extract also reported to possess antifertility efficiency by depleting the oxidative potential of cauda epididymal spermatozoa. Administration of the seed extract at the dose of $10 \mathrm{mg} / \mathrm{kg}$ b.w to experimental animal models for a period of 15 days resulted significant decrease in the level of AST, ALT, glutamate dehydrogenase, Citric acid, and Isocitrate dehydrogenase was observed. Sperm motility was also decreased in the animal model group treated with plant extract. Decreased oxidative potential in the cauda epididymal spermatozoa indicates the antifertility effect of $S$. surattense seeds (Thirumalai et al., 2012).

Dixit and Gupta (1982) reported the anti spermatogenic property of solasodine, an alkaloid found in S. surattense fruits. Administration of solasodine at $20 \mathrm{mg} / \mathrm{kg}$ to experimental animal models for the duration of 30 days resulted that testicular lesions and severe impairment of spermatogenesis. Analysis of biochemical like total protein, sialic acid, and glycogen contents of the testis and epididymis were significantly reduced, whereas the level of testicular cholesterol was increased. Administration of solasodine to castrated dogs, failed to stimulate the epididymal growth. Treatment with solasodine on experimental animals (dogs) affected the male fertility by affecting the androgenesis. Absence of sperms in the cauda epididymis and ductus defens rendered the male infertile. The findings of these investigations confirm the antifertility role of $S$. surattense fruit and seed extracts.

\section{Fertility activity}

The post-menopausal syndrome is characterized by low estrogen levels, leading to sexual dysfunction, vaginal dystrophy, and osteoporosis. Solanum surattense is reported to possess fertility activity by promoting conception in females. Studies on postmenopausal ovariectomized animal models by the administration of $S$. surattense extract at doses 200 and $400 \mathrm{mg} /$ $\mathrm{kg}$ for duration of 90 days resulted that increased serum estradiol content, vaginal cornification and uterine weight. Fertility effect was similar to the effect of standard drug $\beta$-estradiol. At doses
$200 \mathrm{mg} / \mathrm{kg}$ exhibited the potent estrogenic activity, but at higher doses it induces negative feedback inhibition (Aswar et al., 2014). These findings suggest the potential ability of $S$. surattense in preventing the post-menopausal symptoms associated with estrogen deficiency by promoting the estrogen levels.

\section{Antinociceptive activity}

Rahman et al. (2003) studied the antinociceptive activity of $S$. surattense on experimental animal models. Methanol extracts of $S$. surattense significantly suppressed the frequency of acetic acid induced abdominal constrictions in animal models. At dose $500 \mathrm{mg} / \mathrm{kg}$ reduced the frequency of worthiness and showed the $73.08 \%$ inhibition. S. surattense exhibited the antinociceptive efficiency in a dose-dependent manner.

\section{Anti-piles activity}

The Ayurvedic text mentioned that $S$. surattense possess anti piles activity (Pandey et al., 2018). Indian tribe to cure piles since from the ancient past has used a root of $S$. surattense, as a traditional medicine. Still, it is practiced in many regions of India because of its remarkable curative properties. There are no scientific reports until now. Systematic investigation and isolation of bioactive agents, which are effective to cure piles from the crude extracts of $S$. surattense roots, provide the possibility for the development of effective drug than the available ones.

\section{Acute toxicity studies}

Studies on leaf and fruits extracts of $S$. surattense revealed that, plant extracts are non-toxic in nature, even at higher dose 2,000 mg/kg (Gupta et al., 2011; Ahmed et al., 2016; Pingale, 2013). Intake of steroidal glycosides (Solanaceae) led to acute intoxication and severe cases cause death, but no adverse effect of $S$. surattense reported so far (Langkilde et al., 2009).

\section{CONCLUSION AND PERSPECTIVES}

Solanum surattense has been used in the traditional Indian medicine (Ayurveda) to cure for various ailments since from the ancient times and also practiced by the folklore. Phytochemical investigation on roots, leaves, and fruits revealed the presence of secondary metabolites like flavanoids, alkaloids, phenols saponins, glycosides, steroids, and triterpinoids. Intensive investigations on phytochemical constituents of $S$. surattense reported the presence of glycoalkolid solasonine, steroidal alkaloids solanocarpine, solasonine, solamargine, carpesterol, and diosgenine. Folklore claims in its traditional usage to cure various ailments propheled to carry out various phamacognostic activities by the phytochemists. Phamacognstic activities like antimicrobial, anihelmenthic, antihyperglycemic, hypolipidemic, cardiovascular protective effect, antiulcer, wound healing, uriolithiatic, and antifertiltiy are extensively investigated by many researchers. Systematic investigation and clinical trials validate the folklore claims and traditional use of $S$. surattense for its versatile therapeutic effects. Extensive survey of literature revealed that number of compounds isolated from this multitherapeutic medicinal plant, but the limitation is only a few of them is studied for its potent biological activity. The present review suggests that current literature on pharmacological activities proved to be a multitherapeuticmedicinal plant. Further 
exploration of bioactive compounds from $S$. surattense and its validation promises the possibility to exploit and develop novel chemotherapeutic drugs from this natural resource.

\section{ACKNOWLEDGMENTS}

T. Siva Kumar (SRF) was grateful to University Grants Commission (UGC), New Delhi, for awarding BSR-RFSMS/SRF research fellowship.

\section{REFERENCES}

Abbas K, Niaz U, Hussain T, Saeed MA, Javaid Z, Idrees A, Rasool S. Antimicrobial activity of fruits of Solanum nigrum and Solanum xanthocarpum. Acta Pol Pharm, 2014; 71(3):415-21.

Ahmed MM, Andleeb S, Saqib F, Hussain M, Khatun MN, Ch BA, Rahman H. Diuretic and serum electrolyte regulation potential of aqueous methanolic extract of Solanum xanthocarpum fruit validates its folkloric use in dysuria. BMC Complement Altern Med, 2016; 16:166.

Alelign T, Petros B. Kidney stone disease: an update on current concepts. Adv Urol, 2018; 2018:3068365.

Antony HA, Parija SC. Antimalarial drug resistance: an overview. Trop Parasitol, 2016; 6(1):30-41.

Anwikar S, Bhitre M. Study of the synergistic anti-infl ammatory activity of Solanum xanthocarpum Schrad and Wendl and Cassia fi stula Linn. Int J Ayurveda Res, 2010; 1:167-71.

Aswar U, Gurav M, More G, Rashed K, Aswar M. Effect of aqueous extract of Solanum xanthocarpum Schrad. \& Wendl. on postmenopausal syndrome in ovariectomized rats. J Integr Med, 2014; 12(5):439-46.

Babu NP, Pandikumar P, Ignacimuthu S. Anti-inflammatory activity of Albizia lebbeck Benth., an ethnomedicinal plant, in acute and chronic animal models of inflammation. J Ethnopharmacol, 2009; 125(2):356-60.

Bahuguna Y, Juyal V, Gusain K. Pharmacological evaluation of Solanum surattense leaves for antiulcer activity. J Pharm Res, 2008; 2:253-9.

Bansal SK, Singh KV, Kumar S. Larvicidal activity of the extracts from different parts of the plant Solanum xanthocarpum against important mosquito vectors in the arid region. J Environ Biol, 2009; 30(2):221-6.

Bansal SK, Singh KV, Sharma H. Synergistic efficacy of Solanum xanthocarpum and Wthinia somnifera on larvae of mosquito vector species. J Environ Biol, 2015; 36:633-8.

Barik CS, Parida N, Sahu D, Sahoo AR. Solanum surattense: evaluation of anthelmintic activity. J Pharm Adv Res, 2018; 1(5):240-6.

Bhutani KK, Paul AT. Apoptosis inducing activity of steroidal constituents from Solanum xanthocarpum and Asparagus racemosus. Phytomedicine, 2010; 17(5):789-93.

Burger T, Mokoka T, Fouché G, Steenkamp P, Steenkamp V, Cordier W. Solamargine, a bioactive steroidal alkaloid isolated from Solanum aculeastrum induces non-selective cytotoxicity and P-glycoprotein inhibition. BMC Complement Altern Med, 2018; 18(1):137.

Cham, BE. Solasodine, solamargine and mixtures of solasodine rhamnosides: pathway to expansive clinical anticancer therapies. Internat $\mathrm{J}$ Clin Med, 2017; 8:692-713.

Chauhan N, Kumar D, Kasana M. Medicinal plants of Muzaffarnagar district used intreatment of urinarytract and kidney stones. Ind J Trad Knowl, 2009; 8:191-5.

Dewangan H, Bais M, Jaiswal V, Verma VK. Potential wound healing activity of the ethanolic extract of Solanum xanthocarpum schrad and wendl leaves. Pak J Pharm Sci, 2012; 25(1):189-94.

Divya K, Ankit K, Tripathi JS, Tiwari SK. In-vitro and in-vivo assessment of anti-asthmatic activity of polyherbal ayurvedic drug. IOSR J Pharm Biol Sci, 2013; 6:60-70.

Dixit VP, Gupta RS. Antispermatogenic/antiandrogenic properties of solasodine $(\mathrm{C} 27 \mathrm{H} 43 \mathrm{O} 2 \mathrm{~N})$ obtained from Solanum xanthocarpum berries on the male genital tract of dog (Canis-familiaris). A histophysiological approach. Int J Androl, 1982; 5(3):295-307.

Ghildiyal S, Joshi VK. Pharmacognostical studies on Solanum surrattence burm f. Root. 2014; 3(4):240-5.

Gonzalez AC, Costa TF, Andrade ZA, Medrado AR. Wound healing-a literature review. An Bras Dermatol, 2016; 91(5):614-20.

Govindan S, Viswanathan S, Vijayasekaran V, Alagappan R. A pilot study on the clinical efficacy of Solanum xanthocarpum and Solanum trilobatum in bronchial asthma. J Ethnopharmacol, 1999; 66(2):205-10.

Gupta RK, Hussain T, Panigrahi G, Das A, Singh, GN, Sweety K, Faiyazuddin M, Rao CV. Hepatoprotective effect of Solanum xanthocarpum fruit extract against $\mathrm{CCl} 4$ induced acute liver toxicity in experimental animals. Asian Pac J Trop Med, 2011a; 4(12):964-8.

Gupta R, Sharma AK, Dobhal MP, Sharma MC, Gupta RS Antidiabetic and antioxidant potential of $\beta$-sitosterol in streptozotocininduced experimental hyperglycemia. J Diabetes, 2011b; 3(1):29-37.

Hashmi S, Al-Salam S. Acute myocardial infarction and myocardial ischemia-reperfusion injury: a comparison. Int J Clin Exp Pathol, 2015; 8(8):8786-96.

Heble MR, Narayanaswamy S, Chadha MS. Hormonal control of steroid synthesis in Solanum xanthocorpum tissue cultures. Phytochemistry, 1971; 10(10):2393-4.

Huque A, Biswas S, Abdullah-Al-Mamun Md, Bhuiyan JR, Md. Harun ur Rashid Md, Jahan A. Analgesic, anti-inflammatory and anxiolytic activity evaluation of methanolic extract of Solanum xanthocarpum Leaf in swiss albino mice model. IJPCR, 2015; 7(1):68-76.

Jalali Ghassam B, Ghaffari H, Prakash HS, Kini KR. Antioxidant and hepatoprotective effects of Solanum xanthocarpum leaf extracts against CCl4-induced liver injury in rats. Pharm Biol, 2014; 52(8):1060-8.

Jayakumar K, Murugan K. Solanum alkaloids and their pharmaceutical roles: a review. J Anal Pharm Res, 2016; 3(6):00075.

Kaushik NK, Bagavan A, Rahuman AA, Zahir AA, Kamara C, Elango G, Jayaseelan C, Kirthi AV, Santhoshkumar T, Marimuthu S, Rajakumar G. Evaluation of antiplasmodial activity of medicinal plants from North Indian Buchpora and South Indian Eastern Ghats. Malar J, $2015 ; 14: 65$.

Khanam S, Sultana R. Isolation of $\beta$-sitosterol and stigmastero as active immunomodulatory constituent from the fruits of Solanum xanthocarpum (Solanaceae). IJPSR, 2012; 3(4):1057-60.

Kumar N, Prakash D, Kumar P. Wound healing activity of Solanum xanthocarpum Schrad. \& Wendl fruits. Indian J Nat Prod Res, 2010; 1(4):470-5.

Kumar S, Pandey AK. Phenolic content, reducing power and membrane protective activities of Solanum xanthocarpum root extracts. Vegetos, 2013; 26:301-7.

Kumar S, Pandey AK. Medicinal attributes of Solanum xanthocarpum fruit consumed by several tribal communities as food: an invitro antioxidant, anticancer and anti HIV perspective. BMC Complement Altern Med, 2014; 14:112.

Kuok W, Hsu SH, Li YP, Lin WL, Liu LF, Chang LC, Lin CC, Lin CN, Sheu HM. Anticancer activity evaluation of the Solanum glycoalkaloid solamargine: triggering apoptosis in human hepatoma cells. Biochem Pharmacol, 2000; 60:1865-1873.

Langkilde S, Mandimika T, Schrøder M, Meyer O, Slob W, Peijnenburg A, Poulsen M. A 28-day repeat dose toxicity study of steroidal glycoalkaloids, alpha-solanine and alphachaconine in the Syrian Golden hamster. Food Chem Toxicol, 2009; 47(6):1099-108.

Madhavi HR, Neha KS, Saininand SA, Nikhil CT, Deepa RV. A holistic approach on review of Solanum virginianum. L. RRJPPS, 2014; $3(3): 1-4$.

Mahesh Kumar P, Murugan K, Kovendan K, Panneerselvam C, Prasanna Kumar K, Amerasan D, Subramaniam J, Kalimuthu K, Nataraj T. Mosquitocidal activity of Solanum xanthocarpum fruit extract and copepod Mesocyclops thermocyclopoides for the control of dengue vector Aedes aegypti. Parasitol Res, 2012; 111(2):609-18. 
Mohan L, Sharma P, Srivastava CN. Evaluation of Solanum xanthocarpum extracts as mosquito larvicides. J Environ Biol, 2005; 26(Suppl 2): 399-401.

Mohan L, Sharma P, Srivastava CN. Comparative efficacy of Solanum xanthocarpum extracts alone and in combination with a synthetic pyrethroid, cypermethrin, against malaria vector, Anopheles stephensi. Southeast Asian J Trop Med Public Health, 2007; 38(2):256-60.

Muruhan S, Selvaraj S, Viswanathan PK. In vitro antioxidant activities of Solanum surattense leaf extract. Asian Pac J Trop Biomed, 2013; 3(1):28-34.

Nithya M, Ragavendran C, Natarajan D. Antibacterial and free radical scavenging activity of a medicinal plant Solanum xanthocarpum. Int J Food Prop, 2018; 21(1):328-42.

Panday HP. Seed fume of Solanum surattense: a traditional panacea for teeth and gums. Indian J Tradit Knowl, 2004; 3(2):206-7.

Pandey RK, Shukla SS, Jain A, Jain A, Gupta VB, Deb L. Evaluation of comparative immunomodulatory potential of Solanum xanthocarpum root and fruits on experimental animal. Indian J Pharm Educ Res, 2018, 52(4 Suppl 2):s237-45.

Parmar S, Gangwal A, Sheth N. Solanum xanthocarpum (Yellow Berried Night Shade): a review. Der Pharmacia Lett, 2010; 2(4):373-83.

Parmar KM, Itankar PR, Joshi A, Prasad SK. Anti-psoriatic potential of Solanum xanthocarpum stem in imiquimod-induced psoriatic mice model. J Ethnopharmacol, 2017; 198:158-66.

Patel PK, Patel MA, Vyas BA, Shah DR, Gandhi TR. Antiurolithiatic activity of saponin rich fraction from the fruits of Solanum xanthocarpum Schrad. \& Wendl. (Solanaceae) against ethylene glycol induced urolithiasis in rats. J Ethnopharmacol, 2012; 144(1):160-70.

Pingale SS. Evaluation of acute toxicity for Solanum xanthocarpum fruits. BioMedRx, 2013; 1(3):330-2.

Poongothai K, Ponmurugan P, Ahmed KS, Kumar BS, Sheriff SA. Antihyperglycemic and antioxidant effects of Solanum xanthocarpum leaves (field grown $\&$ in vitro raised) extracts on alloxan induced diabetic rats. Asian Pac J Trop Med, 2014; 4(10):778-85.

Potapovich MV, Metelitsa DI, Shadyro OI. Antioxidant activity of hydroxy derivatives of coumarin. Appl Biochem Microbiol, 2012; 48:250-6.

Priya P, Pal JA, Aditya G, Gopal R. Anti-microbial, anti-oxidant and anthelmintic activity of crude extract of Solanum xanthocarpum. Pharmacognosy J, 2010; 2(11):400-4.

Pulice G, Pelaz S, Matías-Hernández L. Molecular farming in artemisia annua, a promising approach to improve anti-malarial drug production. Front Plant Sci, 2016; 7:329.

Pullaiah CP, Dhanunjaya S, Narasimha Kumars GV, Pichaiah D, Venkateswarlu M, Ranganayakulu D. Impact of Solanum surettense on membrane bound $\mathrm{Na}+/ \mathrm{K}+$ ATPase and in vivo anti-oxidants activity on isoproterenol induced myocardial injury in rats. J Phytopharm, 2015; 4(3):139-42.

Purohit A. Contraceptive efficacy of Solanum xanthocarpum berry in male rats. Anc Sci Life, 1992; 12(1-2):264-6.

Rahman MT, Ahmed M, Alimuzzaman M, Shilpi JA Antinociceptive activity of the aerial parts of Solanum xanthocarpum. Fitoterapia, 2003; 74(1-2):119-21.

Ramanarayana Reddy RV, Uma Maheshwara Rao K, Vangoori Y, Mohana Sundharam J. Evaluation of diuretic and anti-inflammatory property of ethanolic extract of Solanum surattense in experimental animal models. Int J Pharm Pharm Sci, 2014; 6(1):387-9.

Ramazani A, Zakeri S, Sardari S, Khodakarim N, Djadidt ND. In vitro and in vivo anti-malarial activity of Boerhavia elegans and Solanum surattense. Malar J, 2010; 12(9):124.

Rehman Shah MA, Khan H, Khan S, Muhammad N, Ullah Khan F, Muhammad A, Khan YM. Cytotoxic, antioxidant and phytotoxic effect of Solanum surattense burm F fruit extracts. Int J Pharmacogn Phytochem, 2013; 28(2):1154-58.
Sahle T, Okbatinsae G. Phytochemical investigation and antimicrobial activity of the fruit extract of Solanum incanum grown in Eritrea. Ornamental Med Plants, 2017; 1(1):15-25.

Saiyed IZ, Kanga DD. Chemical examination of the fruits of Solanum xanthocarpum. Proc Indian Acad Sci, 1936; 4(3):255-60.

Sen S, Chakraborty R. Revival, modernization and integration of Indian traditional herbal medicine in clinical practice: importance, challenges and future. J Tradit Complement Med, 2016; 7(2):234-44.

Sethi G, Shanmugam MK, Warrier S, Merarchi M, Arfuso F, Kumar AP, Bishayee A. Pro-apoptotic and anti-cancer properties of diosgenin: a comprehensive and critical review. Nutrients, 2018; 10(5):E645.

Sharma N, Sharma AK, Zafar R. Kantikari: a prickly medicina weed ecosensorium. J Phytol Res, 2010; 9(1):13-17.

Sheeba E. Antibacterial activity of Solanum surattense burm. f. Kathmandu Univ J Sci Eng Technol, 2010; 6:1-4.

Singh H, Prakash A, Kalia AN, Majeed AB. Synergistic hepatoprotective potential of ethanolic extract of Solanum xanthocarpum and Juniperus communis against paracetamol and azithromycin induced liver injury in rats. J Tradit Complement Med, 2015; 6(4):370-6.

Singh OM, Singh TP. Phytochemistry of Solanum xanthocarpum: an amazing traditional healer. J Sci Ind Res, 2010; 69:732-40.

Singh OM, Subharani K, Singh NI, Devi NB, Nevidita L. Isolation of steroidal glycosides from Solanum xanthocarpum and studies on their antifungal activities. Nat Prod Res, 2007; 21(7):585-90.

Sridevi M, Kalaiarasi P, Pugalendi KV. Antihyperlipidemic activity of alcoholic leaf extract of Solanum xanthocarpum in streptozotocindiabetic rats. Asian Pac J Trop Biomed, 2011; 1(Suppl 2):276-80.

Sridevi M, Senthil S, Pugalendi KV. Antihyperglycemic effect of Solanum xanthocarpum leaf-extract in streptozotocin induced diabetic Rats. J Pharmacol Toxicol, 2007; 2:621-9.

Thirumalai T, David E, Viviyan TS, Elumalai EK. Effect of Solanum xanthocarpum seed on the oxidative potential of cauda epididymal spermatozoa. Asian Pac J Trop Biomed, 2012; 2(1):21-3.

Vijay Amirtharaj L, Srinivasan N, Sireesha A, Karthikeyan K, Mahalaxmi S. Evaluating the analgesic efficacy of Solanum surattense (Herbal Seed Extract) in relieving pulpal pain-an in-vivo study. Dentistry, $2015 ; 5: 4$

Witaicenis A, Luchinp AC, Hiruma-Lima CA, Felisbino SL, Justulin LA Jr. Mechanism and effect of esculetin in an experimental animal model of inflammatory bowel disease. Eur J Inflamm, 2013; 11(2):433-46.

Wunsch G, Gourbin C. Mortality, morbidity and health in developed societies: a review of data sources. Genus, 2018; 74(1):2.

Yadav A, Bhardwaj R, Sharma RA. Free radical scavenging potential of the Solanum surattense burm f.: an important medicinal plant. Int J Pharm Pharm Sci, 2014; 6(3):39-42.

Zanini A, Cherubino F, Zampogna E, Croce S, Pignatti P, Spanevello A. Bronchial hyperresponsiveness, airway inflammation, and reversibility in patients with chronic obstructive pulmonary disease. Int $\mathrm{J}$ Chron Obstruct Pulmon Dis, 2015; 10:1155-61.

How to cite this article:

Tekuri SK, Pasupuleti SK, Konidala KK, Amuru SR, Bassaiahgari P, Pabbaraju N. Phytochemical and pharmacological activities of Solanum surattense burm. f.-A review. J Appl Pharm Sci, 2019; 9(03):126-136. 